\title{
Plant Breeding Training in the U.S.
}

\author{
P. Stephen Baenziger \\ Department of Agronomy and Horticulture, University of Nebraska, Lincoln, NE 68583-0915
}

The plant breeding enterprise is large and highly interdisciplinary. In considering how to approach this topic, it is necessary to define who is a plant breeder for that defines the scope of this paper. For the purpose of this paper, a plant breeder will be defined as a person who is actively involved in creating new plant germplasm that may lead to new cultivars or be used as parents to create new cultivars of food, feed, fiber, and ornamental plants. This definition is deliberately narrow. For example it does not include those who are developing molecular markers for marker assisted selection, unless the scientist is involved in the selection process. Nor would it include a germplasm evaluator unless he or she is actively involved in using some of the evaluated lines to create new germplasm. Plant breeders often work in teams, which can include geneticists, cytogeneticists, plant evolutionists, biochemists, plant pathologists, entomologists, cereal or other end-use quality chemists, statisticians, and plant production specialists. These fields are very important in plant improvement, but their educational needs are different than those of plant breeders.

\section{THE DEMOGRAPHICS OF PLANT BREEDING}

In reviewing the educational needs of plant breeders, it is helpful to know who currently does plant breeding (Table 1, adapted from Frey, 1996). A more recent survey is being developed (A.M.Thro, personal communication), but Frey (1996) is the most recent complete report on the human capital involved in plant breeding. The summary data in Table 1 is in science person years (the amount of time a full time person would work for one year). For simplicity, the science person years will be called scientists or breeders with the understanding that the actual number of plant breeders exceeds those reported in the table because many breeders have additional duties. For example, a breeder can split his or her time between breeding two or more plants, or with teaching and plant breeding research, etc. If a university plant breeder had $50 \%$ teaching appointment and a 50\% research appointment where he or she worked equally on breeding new oat (Avena sativa L.) and barley (Hordeum vulgare L.) cultivars, their breeding contribution reported in Table 1 would be 0.25 scientist years for barley breeding and 0.25 scientist years for oat breeding. With recent consolidations in commercial plant breeding the current numbers may be slightly lower than those for 1996, however the rough proportions will be similar. In 1996, there were 2205 plant breeders and about $68 \%$ were employed in the private sector, $24 \%$ were employed at universities, and the remaining $8 \%$ were employed by the U.S. Department of Agriculture (USDA). Hence, about 2 out of every 3 graduate students who are trained in plant breeding will work in the private sector. For any crop, the proportion will vary, but generally the range would be somewhere between 3 to 4 out of 5 graduate students will work in the private sector in the future. Of these 2205 breeders, about 40\% (892 breeders) were involved in cereal breeding, with the majority of the cereal breeders [598.5 (67\%) out of 892] working in some aspect of corn (Zea mays L.) breeding (Table 2, adapted from Frey, 1996). In corn breeding, most breeders are in the private sector $(93 \%)$. In cereals, $79 \%$ of all breeders are in the private sector. If cereals are removed from Table 1, the proportion of private breeders would be $61 \%$. While most of the breeders listed in Tables 1 and 2 will have a $\mathrm{PhD}$ degree, the MS and BS level plant breeders are probably similarly distributed among the public and private sector.

The data clearly show that most students will need to be educated so that they can succeed in a commercial setting. The question therefore needs to be asked as to whether we are realistically training plant breeders for the opportunities that they will have?

For plant breeders who will work in industry, the key question is do they receive sufficient training in the business side of their profession? When I worked for a major company, I was very happy to move to a new facility, but was totally unaware that the new facility was being depreciated against the budget for every employee who worked in the new facility. The costs for an employee in the new facility (due to the depreciation costs) were much higher than a similar employee would cost in an older facility that was fully depreciated. It did not take long for the accountants to decide the costs were too high per project in the new facility, so they cut employees - a dubious decision because it just raised the cost per employee in the new facility, as there were fewer employee to spread the depreciation costs over. However, it did reduce the overall research cost for projects based in the new facility. Similarly, when the company acquired another large company, there were greater costs for interest payments on the loans needed to acquire the second company, and the funds for research received additional scrutiny. Only the critical research areas were continued and much of the exploratory research was reduced through lay-offs. These experiences were very personal encounters with the business side of private sector research, how it affected my colleagues, and how it is useful to understand the business side of your profession as you plan a career. Understanding the business side of one's profession can also greatly help in negotiating with the project managers who may or may not be scientists, but will most likely report to nonscientist managers.

Another way of considering whether or not new plant breeders are receiving adequate education for the private sector is to review their career paths. Many plant breeders begin their career with an experienced plant breeder. This apprenticeship may reflect a need for the inexperienced plant breeder to be mentored in learning the company policies and germplasm, but it may also reflect a university education that emphasized research and skills that are less suitable for the types of research they will do in the corporate setting. One could ask whether the company hired good scientists but needed to educate them in the practical and nuanced sense of germplasm creation. Also, it would be very interesting to learn the nature and type of training that newly hired plant breeders receive through their companies and how it relates to their university educational training.

For plant breeders who will work in the public sector [university, national programs such as the USDA, Agricultural Research

Table 1. Estimated science person years by crop devoted to plant breeding research and development in the United States in the public (university and USDA-ARS) and private sectors. Plant breeding research and development includes basic plant breeding research, genetic enhancement, and cultivar development. Data is from Frey (1996).

\begin{tabular}{lcrrr}
\hline Crop category & University & USDA-ARS & Industry & Total \\
\hline Cereal & 155 & 34 & 703 & 892 \\
Forage & 20 & 13 & 103 & 136 \\
Fiber & 38 & 33 & 51 & 122 \\
Fruit and vegetable & 38 & 8 & 167 & 213 \\
Grain legume & 67 & 14 & 126 & 207 \\
Lawn and turf & 15 & 0 & 41 & 56 \\
Leafy, bulbous, and stem vegetables & 16 & 2 & 77 & 95 \\
Medicinal, spice, and special crops & 6 & 4 & 5 & 15 \\
Mushroom & 1 & 0 & 2 & 3 \\
Oilseed & 24 & 6 & 74 & 104 \\
Ornamental & 18 & 5 & 24 & 87 \\
Root and tuber & 45 & 12 & 5 & 81 \\
Stimulant & 13 & 2 & 25 & 20 \\
Sugar & 4 & 15 & 32 & 44 \\
Temperate fruit and nut & 50 & 23 & 0 & 105 \\
Tropical fruit and nut & 10 & 6 & 0 & 16 \\
Miscellaneous & 9 & 0 & 1499 & 9 \\
Total & 529 & 177 & & 2205 \\
\hline
\end{tabular}


Service (ARS), or foundations], the question is do they receive sufficient training in the academic or public side of their profession. Are they formally trained so they can teach or be an extension educator? Are they trained in the idiosyncrasies of academic culture? For example, how does a plant breeder who needs a minimum of 7 years to develop a cultivar maneuver through promotion and tenure? My favorite example of this concern are those who breed long generation plants such as the black walnut tree (Juglans nigra L.) breeder where it takes 7 to 10 years to identify useful young trees that may be grafted (another 5 to 7 years) for replicated trials and 60 years for a truly mature plant life cycle evaluation (K. Woeste, personal communication). Another concern in training public plant breeders is their learning how to fund their research, especially in the current nationally competitive research climate that prefers to fund curiosity-driven research in 3- to 5-year increments. The translational or application sciences are underfunded for those working in the public sector and for training students that will become private sector plant breeders where creating new products is the goal. Another concern is that long-term, applied plant breeding projects are unsuitable for the timely matriculation of graduate students.

Finally, it should be considered, what kind of postdoctoral experiences are beneficial for plant breeders? While they may learn new technologies, very few postdoctoral projects lead to an improved breeding philosophy due to their short duration. It should be remembered that postdoctoral positions were not required for plant breeders 30 years ago most likely because there was neither the funding, nor the opportunity to become greatly more skilled in those positions. The postdoctoral experience was simply the early years in the faculty, foundation, or federal agency position or the apprenticeship position with a senior breeder in industry.

The breeding demographics also highlight the divergent philosophies on which crops should be used for educating plant breeders. Basically, what is the right balance between the private need and the public good? Is it best to train plant breeders in crops where they may eventually find a position, e.g., corn where there are massive private sector resources $(25 \%$ of all plant breeders work in private sector corn breeding) and the market is highly privatized, or would it be better to devote public research dollars for breeding education to focus on those crops that are still largely public sector crops and where the private sector does not invest, e.g., tropic fruit and nut, or would it be better to strengthen the breeding efforts in less researched crops that may lack a critical mass to take advantage of their germplasm and genomics? These divergent philosophies continue to be important issues facing the field of public policy as it relates to educating plant breeders.

\section{PUBLIC AND PRIVATE CAREER PATHS: ARE THERE AND SHOULD THERE BE TWO TRACKS?}

Many students receive their training without knowing whether they are going to be a public or private sector plant breeder and as a result, their educational program should be fundamental to careers in both areas. However, it is interesting that there is relatively little data on how often breeders move from the public to private sector and vice versa (scientific career exchanges). From personal experience as one who worked first for the USDA-ARS, then Monsanto, and currently for the University of Nebraska, it was relatively easy for me to return to the public sector because my research career and publications had begun in the public sector. However, my career changes probably benefited by my working for Monsanto for less than three years (hence was still very close to my public sector research career when I decided I would like to return to academia and teach). Also, I worked mainly as an administrator, and did not work for Monsanto in a plant breeding capacity, which would require a longer service to indicate if I were a competent plant breeder. Without summarized or peer-reviewed data, personal experience indicates that career changes happen most easily with young scientists before they have built a reputation and with senior scientist who have built extensive reputations and career portfolios (e.g., professor becoming corporate research directors or research directors becoming public sector administrators).

What is intriguing is that for a field where on average two thirds of their graduates work in the private sector, there are very few professors who have worked in the private sector. Perhaps this dearth of private industry experience, as well as the lack of truly integrated teams on the scale of private enterprise in universities, explains why newly hired plant breeders work with senior breeders to learn the company germplasm and protocols. An important question that needs to be asked is whether it is desirable to have two career paths or should mechanisms be developed for more mid-career exchanges between the public and private sector. If these exchanges are desirable, then means will need to be developed to educate those plant breeders that may switch between the public and private sector. We will also need to learn how to evaluate scientists from the different career paths in ways that allow them to be competitive in the other career path. For example, if a highly

Table 2. Estimated science person years by cereal crop devoted to plant breeding research and development in the U.S. in the public (university and USDA-ARS) and private sectors. Plant breeding research and development includes basic plant breeding research, genetic enhancement, and cultivar development. Data is from Frey (1996).

\begin{tabular}{|c|c|c|c|c|}
\hline Cereal & University & USDA-ARS & Industry & Total \\
\hline Barley & 16.4 & 2.1 & 13.9 & 32.4 \\
\hline Dent Corn & 27.1 & 8.2 & 509.75 & 545.05 \\
\hline Popcorn & 1.2 & 0.1 & 19.4 & 20.7 \\
\hline Sweet Corn & 5.35 & 0.4 & 27 & 32.75 \\
\hline All Corn & 33.65 & 8.7 & 556.15 & 598.5 \\
\hline Millet & 2.55 & 0 & 1.7 & 4.25 \\
\hline Oat & 10.1 & 2.7 & 4.9 & 17.7 \\
\hline Rice & 13.8 & 6.3 & 21.9 & 42 \\
\hline Rye & 0.9 & 0 & 0.1 & 1 \\
\hline Sorghum & 11.8 & 2.5 & 40.8 & 55.1 \\
\hline Triticale & 0.85 & 0 & 8.15 & 9 \\
\hline Wheat & 64.5 & 11.95 & 53.95 & 130.4 \\
\hline Wild rice & 0.8 & 0 & 1.4 & 2.2 \\
\hline Total & 155.35 & 34.25 & 702.95 & 892.55 \\
\hline
\end{tabular}

skilled, successful, and articulate plant breeder with numerous commercially successful inbred lines decided to become a public plant breeder, but had only publications from his $\mathrm{MS}$ and $\mathrm{PhD}$ research, how would he or she be considered for an associate or full professor position with or without tenure? Also, with the propensity of acquisitions and mergers in the seed industry, should the companies allow their breeders to have the kinds of outputs so that they could be more competitive in the public sector if they decided to change their career paths? Is it fair or reasonable to expect the private sector plant breeder to work exclusively for the benefit of the company with little possibility of creating a career that prepares them for the many voluntary or involuntary opportunities that they may have in their professional lifetime?

\section{PLANT BREEDING TRENDS AND POLICY}

The ongoing trends in the breeding industry appear to be for less capacity in the public sector and consolidation in the private sector. In the public sector many former plant breeding positions have been replaced with those in emerging or evolving technologies. Despite considerable resources within the public sector for plant breeding. The challenge to the public sector research community is to make sure those resources devoted to plant breeding are wisely used. The wise allocation of resources may include consolidating programs into major educational centers. Guner and Wehner (2003) found that only a few universities with large plant breeding programs remained in the U.S. It is unclear how many plant breeding centers are needed, but university fortunes ebb and flow and it is best to have some surplus capacity to plan for unexpected changes. Many of the universities with well known plant breeding programs in my youth were not mentioned by Guner and Wehner (2003).

With the advances in communications and information transfer, new models of among university collaboration may be needed where diverse public and private plant breeding programs can be tied together in virtual communities to meet local, regional, and national the continued evolution of positions, there are 
Table 3. Number of hectares planted from 1980 to 2000 in 5 year increments for corn, sorghum, and wheat in the U.S. and Nebraska. Information adapted from http://www.nass.usda.gov/QuickStats/.

\begin{tabular}{lccrc}
\hline & & Corn & Sorghum & $\begin{array}{c}\text { Wheat } \\
(1000 \text { ha })\end{array}$ \\
\hline 1980 & Location & $(1000$ ha $)$ & $(1000$ ha $)$ & 32719 \\
& U.S. & 34037 & 6334 & 1215 \\
1985 & Nebraska & 3159 & 891 & 30592 \\
& U.S. & 33776 & 7405 & 1053 \\
1990 & Nebraska & 3159 & 851 & 31202 \\
& U.S. & 30037 & 4267 & 992 \\
1995 & Nebraska & 3119 & 648 & 27958 \\
& U.S.A. & 28949 & 3819 & 871 \\
& Nebraska & 3240 & 506 & 25332 \\
& U.S. & 32218 & 243 & 709 \\
\hline
\end{tabular}

needs. A major limitation in educating plant breeders is that few, if any, public plant programs have the scale or scope of the large transnational seed companies. Perhaps, collaborations among universities and industry can provide the fertile ground to nurture the types of cooperation that will be needed in transnational companies. The importance of having the right size and scope to be competitive can not be overestimated as even medium sized seed companies are being purchased by larger companies because the medium sized companies no longer have the capacity to compete for the proprietary traits and technology that large seed companies can purchase or create. On a global perspective, the large international companies continue to grow, the international crop centers are receiving proportionately less funding, as are most researchers in the public sector. The conclusion is that currently public sector plant breeding has lost value in the eyes of the citizen base that funds it.

Some of the trends mentioned above are symptomatic of major, ongoing policy debates that proposes that private enterprise should develop products and public research should create new knowledge. This "one size fits all" approach certainly hurts cultivar development for those crops where the private sector does not currently believe sufficient returns on investment can be made. It also affects the kind of training plant breeders receive on those crops that are largely privatized. On these crops, plant breeders may not be trained to do cultivar or hybrid development (impact plant breeding), but rather excellent basic research.

Other policy changes can greatly impact the agricultural research agenda such as farm programs and trade agreements. These policies have broad ranging effects on what crops are planted and where plant breeders are needed. Over the past 25 years (Table 3 ), the area planted in the U.S. to grain corn, sorghum (Sorghum vulgare L.), and wheat have all declined. However the decline in corn was much smaller than the decline in wheat, which was smaller than the decline in sorghum. Using Nebraska as a specific state example, the area planted to corn increased, while the land planted to wheat decreased, as did that for sorghum. The data for Nebraska are included because most universities that train plant breeders build their plant breeding efforts in crops that are important to their state, occasionally the region, or to international funding organizations. The causes for the changes in the area planted to the three crops would be many and may include the relative amount of research that is devoted to the respective crop improve- ment efforts. Corn has benefited by the large private sector investment in its improvement. However, federal farm programs that no longer required growers to keep their base hectares of crops at a certain level were important in the 1980 s, as was the Freedom to Farm Programs in the 1990s by allowing producers to choose the crop with the best return whether that be from market payments or federal support. The North American Free Trade Agreement that allowed greater importation of corn into Mexico reduced the need for export sorghum for feed grain. Similarly today, subsidies for ethanol, sugar quotas that allow a high fructose syrup market to exist, crop insurance programs, trade quarantines, and cheap water policies affect which crops are grown especially those irrigated crops. The purpose of this discussion is not to highlight which crops are or are not benefited by farm and governmental policies, but rather to highlight the difficulty in identifying which crops rationally should be used to train plant breeders in markets which are artificial due to governmental intervention.

\section{PLANT BREEDING IN A GLOBAL ECONOMY}

As agriculture is truly a global industry, its global nature can affect plant breeding training in a very fundamental way. Firstly does plant breeding need to be done in the area where the crop is being grown or can international breeding programs breed internationally and test locally? If the answer is yes, there may be reduced need to train plant breeders in the U.S. because their work could be outsourced similar to other industries. A considerable amount of breeding research is currently being done in India and China where one out of every three people in the world reside. The Indians and Chinese are very astute consumers when it comes to agricultural products and plant breeding programs and they are less expensive than in the U.S. Especially for small hectarage crops, such as vegetables, it may make sense to have the major research programs in India that has huge consumer vegetable markets and test in the U.S. However, the simple truth is that all plant breeding needs to be local to maximize adaptation and the only time plant breeding should be done elsewhere is when there is no other alternative. Intuitively this conclusion makes sense because the literature on plant breeding emphasizes the importance of genotype by environment interactions and multienvironment testing (Allen et al., 1978; Finlay and Wilkinson, 1963; Kang and Gauch,
1996; Yan et al., 2000). Even in small hectarage crops such as vegetables, the economic return per hectare is large and the producers will demand the best adapted crop.

If all plant breeding is local, is all plant breeding technology local? In this case, the answer is clearly no. Most transnational companies and the International Centers for agriculture have central laboratories especially for the support technologies of computer analyses and molecular biology. Furthermore, different regions have competitive advantages when it comes to using technology. These advantages include excellent infrastructure (roads and communications), literate populations, inexpensive and plentiful labor, or economic expectations that allow businesses to be patiently developed. While the success of hybrid corn is legendary (see Duvick and Cassman, 1999; Troyer, 2004) creating hybrid crops requires patience and a level of investment that is rarely found in the private or public sector in the U.S. Most U.S. exploratory efforts in hybrid crops have ended and hybrid crop breeding programs exist only for those with established technologies and markets. It is not by chance that hybrid cotton (Gossypium hirsutum L.) (Ullah etal., 2003), rice(Oryza sativa L.)(FAO, 2004; Peng et al., 1999), wheat, and many other crops are produced outside the U.S. Nor despite the potential advantages of hybrid crops, it is not by chance that there is so little exploratory hybrid research in the U.S.

Hybrid cotton is widely grown in India and the seed is produced by hand pollination where inexpensive and skilled labor allows the seed to be produced economically. In hybrid rice production, ropes are dragged over the field to foster cross pollination and the transplanted field with their low effective seeding rates are found in Asia where hybrid rice is most widely grown. Hybrid wheat, once grown in the U.S. but rarely now, is also being tried in other countries. In India, the main limitation to hybrid wheat development is the level of heterosis and the cost of hybrid seed (about 2.5 times the cost of pureline seed). To reduce the cost of seed, all hybrid trials and grain production fields are planted at one half of the pureline-seeding rate. To foster greater cross-pollination, the conventional equipment used in small farms in India allows for the pollinator rows to be much closer to the female rows (Fig. 1a) than the large equipment use for extensive farming in the U.S. Using cytoplasmic male sterility (CMS, Fig. 1b) instead of chemical hybridizing agents further reduces the seed costs. In addition, recessive characters such as multiple-ovules (Fig. 1c) where each floret produces three seeds, thus potentially greatly increasing the hybrid seed production capability are being studied. Clearly the most extensive research on hybrid crops is being done outside the U.S. and U.S. students can learn much from these global activities. While all breeding may be local, all technology is global.

\section{TRAINING NEEDS OF PRACTICAL PLANT BREEDERS}

One of the reasons why hybrid crop technology is highlighted above is because it is an important technology that is successful in other 
parts of the world and can have huge potential impacts on agriculture. It is also practical plant breeding focused on a significant opportunity that does not require significant laboratory oriented science, so common in the current training of plant breeders. The question in training future plant breeders is whether we have struck the right balance between practical plant breeding questions and the interesting, emerging science that we can do because we now have the tools? In some ways this question is like the story of man looking at the ground under a street lamp in the middle of the night. A passerby asked if he was looking for something and the man responded, "Yes, I lost a $\$ 20$ bill." The passerby asked if he lost it here and the man replied, "No I lost it over there (pointing into the dark), but the light is better here.'

The question of balance is an old one that persists among plant breeders. In 1957 describing how genetics had impacted plant breeding, H.V. Harlan wrote: "The field of plant breeding actually suffered in a way from the greater knowledge we has acquired. Mendel's work was quickly accepted as an enormous advantage in plant science. It was a definite, tangible thing that seemed to take plant breeding from the arts and place it as a science overnight. It captured the imagination of all workers, and genetic at once became a field offering prestige that both soothed and satisfied. A genetic paper gave new dignity to the author. We boys began to get our hair cut and our shoes shined. The effect on plant breeding was calamitous. Good varieties were still produced, but explorations in the field of practical plant breeding were wholly neglected. A few of us eventually realized that there would come a day when the world would recognize the difference between a good geneticist and a poor one, so we went back to thinking about plant breeding. We have undoubtedly lost the resources of many good minds from this field for a time, but they will be back."

\section{EXPLORATIONS IN THE FIELD OF PRACTICAL PLANT BREEDING: GOING HOME}

The major limitations that face plant breeders relate to the three phases of any breeding program (Baenziger and Peterson, 1992): 1) the introduction of variation, 2) the selection of useful variants, and 3 ) the evaluation of the selected variants for possible release. Every plant breeder is faced with identifying adequate germplasm, efficiently incorporating the germplasm, efficient selection procedures, and improved evaluation procedures. Studies in these areas will lead to better plant breeding methods and cultivars. Included in these research areas would be understanding heterosis and gene action, how to economically produce hybrid seed, and creating those freedom-tooperate technologies that allow plant breeders to continue to explore practical plant breeding in an increasingly privatized world.

Throughout this paper, words like explore, research, and scientist have been used because plant breeding is a science. The most disheart- ening phrase to those who still strive to make planting breeding better is "Plant breeding is a numbers game," as if by just having the most numbers, you are assured of your success. Inertia is not enough to be a plant breeder. While numbers are important, a good idea is more important. Good plant breeders have an insatiable sense of curiosity and are interested in making sure however large their program is, that it contains the right lines and materials for their objectives.

As mentioned previously, the trend in public sector plant breeding is for reduced support and the trend in the private sector is towards large seed companies that are formed through growth, acquisition, or alliances, and have large interdisciplinary teams who are global in nature. The question about plant breeding training is will the public sector training programs have the scope and size to train future plant breeders for the companies that most students will work for in the future. The simple answer is most likely not. Hence greater consideration will have to be given to training plant breeders in commercial setting. The training could include using proprietary research materials or some form of collaborative research involving nonproprietary research materials. Fortunately, there already exists a model for this shared education pattern.

Many international students do their coursework in the U.S. and then do their research in their home country. A similar program could be developed for training plant breeders in the private sector. Anumber of subtle incentives for this research program would be that students would have a greater exposure to private sector research, the student would be more likely to be hired by the private sector if that were their goal, the student would have first hand private sector experience if they decide to work in the public sector and train plant breeders, and that private sector researcher by being involved would lessen the distance between the two tracks of public and private plant breeder, thus creating greater opportunities for scientific exchanges between the two career paths.

Alternative educational strategies might be for the public sector to carve out key research areas where the private sector cannot afford to invest, such as the hybridization of crops that are currently pureline or those minor crops where there is currently little plant breeding. Ideally, if the public sector develops a niche area, it will develop the critical mass and interdisciplinary team approach similar to industry that involves multilocation teams and a businesslike allocation of resources.

\section{MEASURING THE HEALTH OF THE PLANT BREEDING PROFESSION}

As we think about the training needs of future plant breeders, knowing the health of the profession is critical. Students need to know what type of careers will be available to them and what their chances are of obtaining a meaningful position. This understanding of the profession is not to imply that there should be a position for every person trained, as clearly many professions train more students than can reasonably expect to find a position. Rather students deserve to know in a transparent manner what their opportunities will be. With the continued acquisitions and program changes in the private sector plant breeding industry, plant breeders should expect to have more than one employer during their career, particularly if the concept of significant scientific exchanges between the public and private sector is embraced. Even with tenured employment, shifts in the relative importance of crops and the need for additional expertise as new technologies are developed will require plant breeders to greatly change their research approaches and teaching courses.

We often hear that the profession needs more plant breeders (e.g., Guner and Wehner, 2003; USDA, 2001) as indicted by industry often providing on the job breeding training

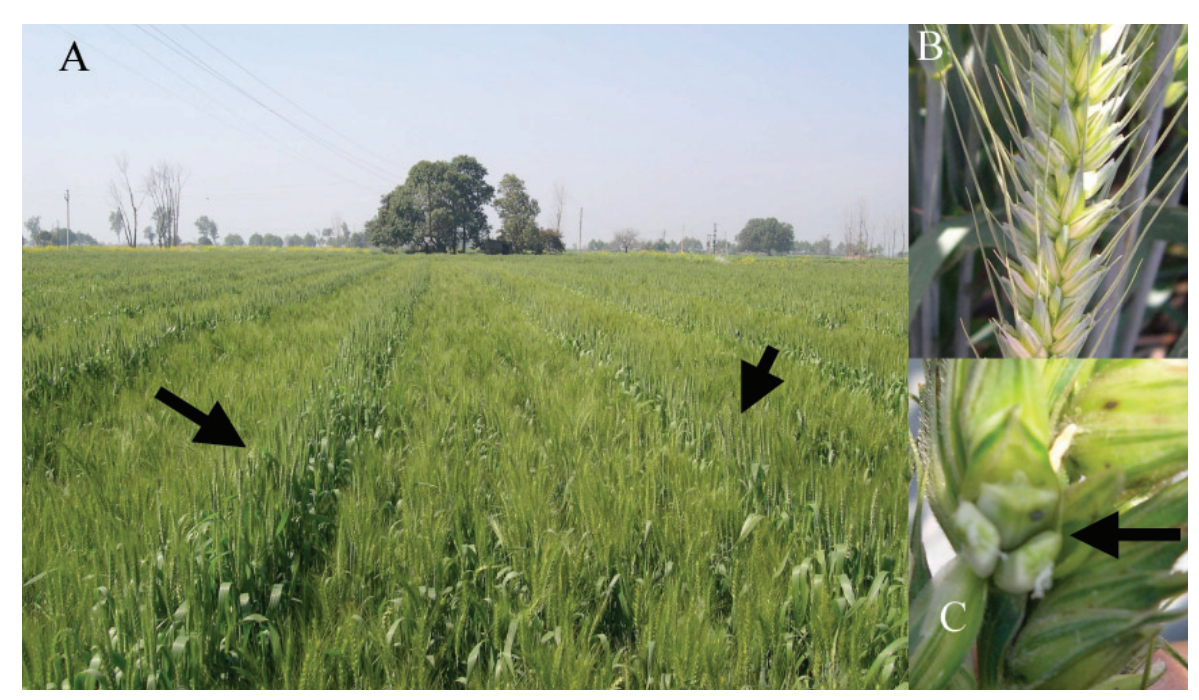

Fig. 1. (A) Hybrid wheat production field in Karnal, India. A single male (see arrows) row is planted about every $1.2 \mathrm{~m}$. Six cytoplasmic male sterile female rows are planted between the male rows. (B) The gaping florets which are indicative of male sterile wheat plants due to cytoplasmic male sterility. (C) The multiple-ovule trait in wheat which three seed are formed per floret (arrow points to three seed being formed in a single floret). 


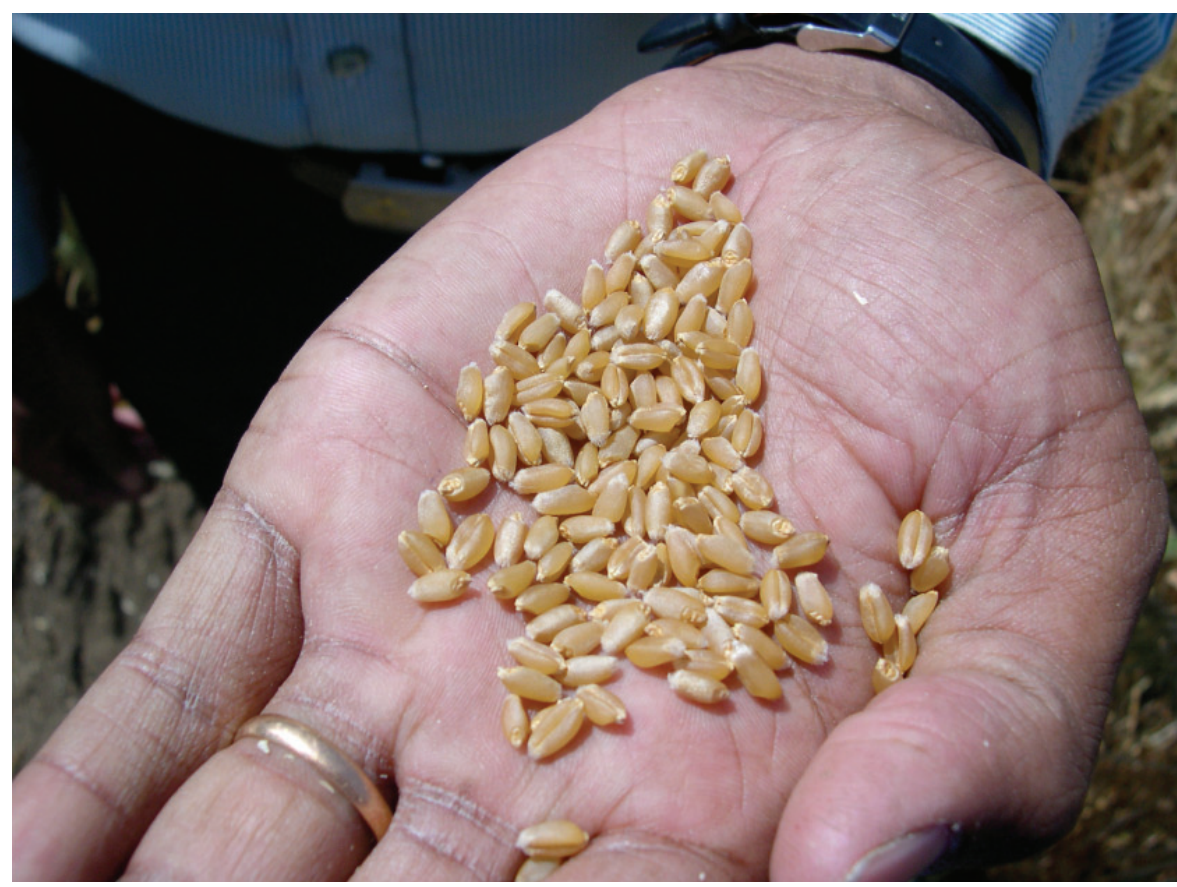

Fig. 2. Experimental hybrid hard white spring wheat in the palm of a plant breeder's hand.

to students trained in other fields, such as biology. However, many established plant breeders have lost their positions in recent acquisitions. It takes them many months to even years to find positions with other companies and rarely are they able to find positions in the public sector. The difficulty that established plant breeders have in finding new positions may actually indicate that we have a surplus of plant breeders. Engineers often lose their jobs in periods of economic decline, but usually they can find positions in other companies once the economy begins to rebound. In some ways, plant breeders are treated as disposable scientists where it is difficult for them to find a new job after a number of years in a position should the company be downsized for any number of reasons. The number of plant breeders who have changed careers (as opposed to positions within a profession) needs to be compared with other fields, but it is surprising that their experience seems undervalued by both the private and public sector.

\section{PORTRAIT OF THE FUTURE PLANT BREEDERS}

Who are the next generation of plant breeders? They are dedicated people who want to change lives for the better. If one reviews the World Food Prize laureates (see http://www. worldfoodprize.org/Laureates/laureates.htm verified April 17, 2005), those who are plant breeders have literally allowed millions of people to survive and many to flourish due to improved genetics in the crops that sustain life. Plant breeders are inveterate optimists who a goal. They may specialize in one or more
$(8,000,000$ acres $)$ - and they remember when they held all the seed of it in the palm of their hand." (Fig. 2) I added "If plant breeders can continue to communicate the positive impact of their science and technology, of what they hold in the palm of their hand, there should never be any trouble in attracting students to plant breeding." Part of training future plant breeders will remain transferring the passion and joy that plant breeders have.

\section{Literature Cited}

Allen, F.L., R.F. Comstock, and D.C. Rasmusson. 1978. Optimal environments for yield testing. Crop Sci. 18:747-751.

Baenziger, P. S. 1990. The challenges of attracting graduate students to plant breeding. J. Agron. Educ. 19:205-210.

Baenziger, P.S. and C.J. Peterson. 1992. Genetic variation: Its origin and use for breeding self-pollinated species, p. 69-92. In:T.M. Stalker and J.P. Murphy (eds.). Plant breeding in the 1990s. Raleigh, N.C.

Duvick, D. N. and K.G. Cassman. 1999. Post-green revolution trends in yield potential of temperate maize in the north-central United States. Crop Sci. 39:1622-1630.

FAO. 2004. Hybrid rice for food security. http://www. fao.org/rice2004/en/f-sheet/factsheet6.pdf.

Finlay, K.W. and G.N. Wilkinson. 1963. The analysis of adaptation in a plant-breeding programme. Austral. J. Agr. Res. 14:742-754.

find the rare cultivar that will succeed. They cherish accountability because plant breeding success is a very measurable trait as witnessed by cultivar distribution surveys or seed sold. By nature they are generalists who are able to pick and chose among technologies to achieve research areas, but they know that whole is much larger than any single part. They believe as Erasmus said "In the kingdom of the blind, the one-eyed man is king." (see http://www. brainyquote.com/quotes/authors/d/desiderius erasmus.html verified April 17, 2005 ) that a little knowledge is better than none for the generalist. They are constantly curious and while respecting the numbers game, they know productivity is the key and search for better ways. Plant breeders embrace change, whether it comes from technology (e.g. increased fertilizer or mechanization) or from biology (e.g. race changes in diseases).

Finally, as an applied plant breeder who has released 29 cultivars, it is clear to me that future plant breeders will surely know the joy of being a plant breeder. In an earlier article on attracting graduate students to plant breeding (Baenziger, 1990), I paraphrased some of the best advice my predecessor (J.W. Schmidt) gave to me: "...there will be three parts to the process of cultivar development that plant breeders will like. The first is making the cross because it requires all the creative and predictive talents as to what may come of the cross. The second is when they walk through their breeding nursery and see a line they know will be released. The third is when that line is grown on $3,200,000$ ha
Frey, K. 1996. National plant breeding study. I Human and financial resources devoted to plant breeding research and development in the United States in 1994. Iowa Agr. Home Econ. Spec. Rpt. 98. Iowa State Univ. Ames.17 Apr. 2005. http://www.ers.usda.gov/Data/PlantBreeding/ Plant\%20Breeding.pdf.

Guner, N. and T.C. Wehner. Survey of U.S. landgrant universities for training of plant breeding students. Crop Sci. 43:1938-1944.

Harlan, H.V. 1957. One man's life with barley. Exposition Press, New York.

Kang. M.S. and H.G. Gauch, Jr. 1996 (eds.). Genotype by environment interaction. CRC Press, Boca Raton, Fla.

Peng, S., K.G. Cassman, S.S. Virmani, J. Sheehy and G.S. Khush. 1999. Yield potential trends of tropical rice since the release of IR8 and the challenge of increasing rice yield potential. Crop Sci. 39:1552-1559.

Troyer, A.F. 2004. Background of U.S. hybrid corn. II. Breeding, climate, and food. Crop Sci. 44:370-380

Ullah, I., M. Kausar Nawaz Shah, and H.-ur-Rehman. 2003. Estimation of essential hybrid vigor levels for economical hybrid cotton production. Asian J. Plant Sci. 2:1004-1007.

U.S. Department of Agriculture. 2001. The future of public plantbreeding programs: Principles androles for the 21st century. USDA Advisory committee on Agr. Biotechnol. Rpt. Mtg. 1-2 Aug. 2001. 17 Apr. 2005. http://www.usda.gov/agencies/biotech/archive/acab/meetings/mtg_8-01/ppbprpt_801.html. USDA, ACAB, Wash., D.C.

Yan, Weikai, L.A. Hunt, Q. Sheng, and Z. Szlavnics. 2000. Cultivar evaluation and mega-environment investigation based on the GGE biplot. Crop Sci. 40:597-605. 